\title{
Mitigating risk: Mediating transition through the enactment of information literacy practices
}

\author{
Abstract \\ Purpose: To present the emergent grounded theory of mitigating risk, which was produced \\ through an analysis of the information literacy practices of English-speakers who are \\ learning a language overseas as part of their undergraduate degree. \\ Design/methodology/approach: The grounded theory emerges from a qualitative study that was \\ framed by practice theory and transitions theory, and employed constructivist grounded \\ theory, semi-structured interviews and photo-elicitation methods to explore the \\ information activities of 26 language-learners from Australia, Canada, the UK and the \\ US.
}

Findings: The grounded theory of mitigating risk illustrates how academic, financial and physical risks that are produced through language-learner engagement overseas catalyse the enactment of information literacy practices that enable students to mediate their transition overseas.

Research limitations/implications: This study's theory-building is localised and contextual rather than generalisable.

Practical implications: The grounded theory broadens librarians' and language-educators' knowledge of student activities during immersive educational experiences as well as extending understanding about the shape that information literacy takes within transition to a new intercultural context.

Social implications: The grounded theory develops understanding about the role that local communities play within intercultural transition and how these groups can respond to and prepare for increasingly fluid patterns of global movement.

Originality/value: This paper contributes to an increasingly sophisticated theoretical conceptualisation of information literacy while further providing a detailed exploration of transition from an information perspective.

Keywords: information literacy; information practices; everyday life; transition

\section{Introduction}

Transition constitutes an important challenge within a number of everyday and organisational scenarios. Political interest in educational mobility, the continued need to migrate or to seek sanctuary and the increasingly fluid nature of the workplace means that there is a growing call to address how people mediate the complexity of change. Transition is further complicated within intercultural settings, which refer to contexts where individuals from different cultures interact (Baldwin \& Hunt, 2002), where it becomes linked to social and digital inclusion as well as to resettlement issues. The need to rebuild understanding whilst working across languages and cultural practices means that transition forms a time of uncertainty as newcomers are forced to deal with the pressures of unfamiliar demands and values. At the same time, transition also forms a time of generative opportunity as people learn how to connect with the sources of knowledge that will support this intensive period of change. The emphasis on the ways in which people rebuild meaning within a new setting illustrates the important role that information, which is defined in this paper as "any difference which makes a difference" (Bateson, 1972, p.459), plays within the mediation of change. The recognition that learning forms the central pivot point of 
transition further positions information literacy, which refers to a "way of knowing the many environments that constitute an individual's being in the world" (Lloyd, 2007, p.182), as the means through which individuals develop the intersubjective understanding that will enable them to navigate the shifts in social role and identity that are necessary within a new setting. The unavoidable and everyday nature of change also illustrates both the need and the impetus for this study's examination of transition from a Library and Information Science (LIS) perspective.

This paper draws upon recently completed doctoral work that explored the information literacy practices of English-speaking students who were learning a language overseas to examine the question of transition through an information lens. This time overseas, which is known as the 'Year Abroad' in the United Kingdom and 'Study Abroad' or 'International Exchange' in the United States, Australia and Canada, forms a critical point within a student's academic study and for their future career plans as they are forced to adapt from learning about to practising a language. The important implications that immersive learning has for the internationalisation of campus as well as within increasingly multicultural working and social environments provide a further illustration of the need to explore transition from an information perspective. To this end, the study was driven by the following research questions:

1. How do language-students enact information literacy practices during time overseas?

2. In what ways do language-students make sense of, transition into and come to know their new information landscapes?

In responding to these questions, this study introduces the grounded theory of mitigating risk, which offers an interpretive, constructivist grounded-theoretical (Charmaz, 2014) understanding and conceptualisation of the ways in which an engagement with information supports languagestudents' transition to new information environments. The grounded theory of mitigating risk illustrates how academic, financial and physical stress that is produced through student engagement overseas catalyses the enactment of information literacy practices that mediate student transition from acting like a language-learner to becoming a language-learner within the structure of their new setting. Drawing attention to the complex dynamics of this time, the theory of mitigating risk consequently has a number of implications for the design of educational programming as well as for thinking about the broader shape of transition within society.

\section{Literature review}

\subsection{Information literacy within intercultural contexts}

Information literacy research that has centred on intercultural contexts has taken a number of different approaches (Hicks \& Lloyd, 2016). The typical emphasis on teaching within information literacy research means that the majority of studies have either focused on exploring information literacy through the lens of national standards and frameworks (e.g. ACRL, 2000) or as the development of learner 'habits of mind' (e.g. Bordonaro, 2006). These studies, which recognise that learners develop creative strategies to work in unfamiliar information environments, provide useful insight into the impact that working in a second or third language has upon academic research practices (e.g. Bordonaro, 2006; Han, 2012; Hughes, 2013). However, they can also be criticised for centring individual processes rather than the broader social dynamics that structure learner engagement within a new information environment. In contrast, the sociocultural perspective that is employed within this study focuses attention on the situated ways in which people engage with information within a specific context. For this reason, 
this review will centre on research that explores how information literacy is shaped by the social site rather than how it is achieved or taught (for a more complete review, please see Hicks \& Lloyd, 2016). A sociocultural approach to information literacy consequently moves the typical focus of intercultural research beyond international students within English-speaking academic contexts to examine the activities of refugees (e.g. Lloyd, Kennan, Thompson \& Qayyum, 2013), immigrants (e.g. Mansour \& Francke, 2017) and bilingual workers (Hicks, 2014), among others.

One of the most important characteristics of studies that take a sociocultural approach to information literacy is the focus on the various information activities that enable an individual to participate within their new setting. Visual activities like observing, for example, which mediate the speed of conversation or a local accent, are seen to predominate when newcomers are working across languages and literacies (Richards, 2015). Observing further enables newcomers to build insight into new community practices as well as to perceive unspoken local rules and regulations, such as when to put rubbish bins out for collection (Lloyd et al., 2013, p.135). Nontextual sources such as the images that are found in junk mail have also been found to help newcomers become oriented to daily life (Lloyd et al., 2013, p.133). Social interaction provides a similarly effective way for refugees and immigrants to access the tacit or taken-for-granted information of a community. Information activities such as pooling, which refers to the combining of fragmented knowledge between co-located fellow nationals, help refugees to develop a "more comprehensive picture" of their information environment (Lloyd, 2015, p.1037) while everyday faith-based spaces facilitate a refugee's connection to informal networks and local ways of knowing (Lloyd \& Wilkinson, 2016). However, while these studies provide a useful starting point for exploring how information literacy is understood within intercultural settings, the emphasis on permanent and often traumatic settlement as well as the lack of attention given to technology illustrates the scope for future research.

\subsection{Information behaviour within intercultural contexts}

Research from the related field of information behaviour further helps to situate this study. Notwithstanding, the emphasis of this paper on learning rather than behaviour means that the review will centre on themes that have been underexplored within information literacy rather than providing a comprehensive examination of information behaviour. While culturally-focused information behaviour studies traditionally centred upon how 'traits' such as race, ethnicity or nationality could be used to predict the shape of an individual's activities, research has since moved beyond demographics to engage with the "contextual, situational, and role variables" (Tsai, 2010) that affect the ways in which individuals engage with information in an intercultural setting. These studies, which, like information literacy research, predominantly centre on the activities of immigrants as well as international students, illustrate the complexity of intercultural information environments. Thus, research highlights the feelings of cultural alienation and emotion that are often heightened within intercultural settings (e.g. Jeong, 2004; Mehra, 2007) as well as the coping strategies that they may adopt within a new setting, including seeking help from locals (Ishimura, 2013) or using technologies such as GPS and social media sites to navigate their new setting (Oh, Butler \& Lee, 2014; Sin \& Kim, 2013). The recognition that olfactory and auditory differences, such as the smell of fish and chips for immigrants (Goodall, 2013, p.126) and the sound of geckos and motorbikes for overseas volunteer tourists (Reed, 2009 , p.55) provide a subtle marker of change further reinforces the important role that a newcomer's body plays in helping to rebuild understanding within a new information environment. At the same time, while Lingel (2014) and Reed (2009) highlight that experience 
impacts the ways in which international newcomers engage with information, the overwhelming emphasis on individuals' initial needs overseas (e.g. Shoham \& Strauss, 2007) illustrates the need for research that engages more concretely with the question of time and the changing nature of participation within a new intercultural setting. Similarly, although Hyldegård and Hertzum (2016) recognise the difficulties that many students have in rebuilding support networks whilst they are studying abroad in Denmark, the lack of attention to non-English majority contexts illustrates a further gap in the literature.

\subsection{Second language acquisition studies}

Scholars from the field of Second-Language Acquisition have carried out various studies into the ways in which language-students engage with information whilst they are overseas. The shape of social support networks forms one of the major strands of this literature, although researchers differ on whether a reliance on friends and family back home as well as groups of co-nationals benefits students' language-learning. While networks may provide emotional (e.g. Lobburi, 2012) or informational support (e.g. Gilhooly \& Lee, 2014), other researchers highlight how dependence on non-native speakers curtails student learning opportunities (e.g. Deakin, 2012). At the same time, and as Gilhooly and Lee (2014, p.389) point out, participation in online communities gives newcomers access to social experiences that may otherwise be denied to them because of "second-language limitations, rural isolation, and outsider status at school and within the host community." Researchers are equally divided on the question of the Internet with several studies warning that excessive online activity runs the risk that students live alongside rather than interacting with local communities (e.g. Mikal, 2011). However, as Martin and Rizvi (2014) illustrate, a binary conception of here and there is simplistic because a migrant's experience of place is made through the ways in which they use technology within a new setting. These ongoing disagreements further demonstrate the need for more extensive critical engagement with these issues from an information perspective.

\subsection{Transition}

The question of transition has been growing in importance within a number of fields, but particularly within the realm of higher education research, policy and practice (Ecclestone, Biesta \& Hughes, 2009; Gale \& Parker, 2014). Political interest in questions of recruitment and retention, including widening participation and workplace learning schemes, has led to the establishment of a number of different approaches to understanding and supporting transition across educational systems. While transition has most traditionally been seen as the navigation of institutional pathways, structures and systems (Ecclestone et al., 2010, p.5), ecological theory has since been used to position transition as a person's change in role when they move "between and across systems" (Dockett \& Perry, 2007, p.6). Most recently, the employment of a sociocultural perspective has defined transition in terms of "people's changing participation in sociocultural activities of their communities" (Rogoff, 2003, p.52). The emphasis on involvement in a community rather than personal or environmental change means that a sociocultural approach characterises transition as 'becoming somebody' in a personal, educational or occupational context (Ecclestone et al., 2010, p.7). For Gale and Parker (2014), these conceptualisations can be understood as taking either an induction, a lifecourse or a becoming approach to transition.

At the same time, growing interest in transition has not yet translated into a detailed examination of international movement. While Volet and Jones (2012) note that studies of international transition are often stigmatised by problematic cultural stereotypes, their literature review focuses almost exclusively on first year undergraduate and formal teaching experiences 
rather than broader questions of study abroad. Similarly, although Jones, Fleischer, McNair and Masika (2018) acknowledge the importance of social bonds and emotional support to international student transition, their study is limited to English-speaking contexts as well as to student participation in foundation years. Transition has been correspondingly side-lined within information research. Although a number of studies have explored the move from secondary to tertiary education (Bent, 2008; Burhanna, 2013; Secker \& Coonan, 2011) as well as between institutions (e.g. Ivins, Copenhaver \& Koclanes, 2017; Nelson, 2017), the emphasis on individual actions has neglected to account for the structural forces that impact student engagement with change. Exceptions are found in Willson's (2016) research, which highlights the important role that institutional goals and the actions of colleagues play in mediating transition, as well as in studies that emphasise the passage from novice to expert (Lloyd \& Somerville, 2006; Moring, 2012) and the need to reconcile established ways of knowing (Lloyd, 2015). Most recently, a handful of studies have focused on the challenges that international students face in their transition to a new academic context (e.g. Cooper \& Hughes, 2017; Hughes, Cooper, Flierl, Somerville \& Chaudhary, 2018). However, the emphasis on the role of the academic library highlights the need for research that explores the processes of international student transition in more detail.

\section{Theoretical Framework}

Situated within an interpretivist framework, this research employs symbolic interactionism (Blumer, 1969) to provide the study's ontological framing, and constructionism (Gergen \& Gergen, 2008) to provide its epistemological structure. The employment of a symbolic interactionist framing, which centres on the premise that individuals act towards things through the (changing) meaning it holds for them (Fine, 1993, p.64), acknowledges the important role that student agency plays in the determination of information activity. The study's use of constructionism, which highlights how human perception, knowledge and social reality are built and sustained through social processes (Burr, 1995, p.4), recognises the plurality of meanings that characterise information and language expertise.

\subsection{Transitions theory}

Transitions theory forms one of the two major sensitising theories through which the findings of this study are analysed. With its roots in anthropology and the idea of a rite of passage (Kralik, Visentin \& van Loon, 2006 p.322), transition theory has most comprehensively been developed within the field of Nursing (Meleis, Sawyer, Messias, Im \& Schumacher, 2000). Notwithstanding, the tendency to flatten "the complexity of social relations" (Fenwick, 2013, p.359) within nursing transitions research means that educational transitions theory (e.g. Perry, Dockett \& Petriwskyj, 2014), which foregrounds questions of agency and power, is used within this study to complement nursing literature. While transitions theory only provides one way in which transition can be explored (see, for e.g. Jones et al., 2018), its well-established theoretical structure as well as its emphasis on sociocultural activity over time meant that it was perceived to form a rich and productive framework for this study.

Change and time form two of the central concepts within transitions theory. Positioning change as the shifts that language-learners make to integrate disruption into their life (cf. Meleis et al., 2000, p.19), transitions theory's emphasis on time also illustrates how student transition is ongoing and in flux rather than forming a linear or a normative 'journey' with distinct stages (Fenwick, 2013, p.362). Personal, social and community conditions (Meleis et al., 2000) 
constitute another core aspect of transitions theory. The importance of personal preparation illustrates how language-student awareness and knowledge alter the ways in which they perceive and respond to change while emphasising how community and social conditions, such as the presence of discrimination or the existence of support groups (Meleis et al., 2000, p.23) both facilitate and inhibit student transition. Lastly, nursing's emphasis on wellbeing means that transitions theory centres indicators and outcomes of transition. However, given that the complexity of learning practices means that 'successful' transitions are often hard to depict, this study draws upon educational transitions theory to position language-student transition as marked by their ongoing and increasingly knowledgeable participation within the activities of their community (Rogoff, 2003) rather than as a managed process that is centred on normative milestones. In sum, the emphasis on situated interaction means that this study's use of transitions theory draws attention to the structural forces that impact language-student engagement with change as well as the multiple ways in which they mediate the impact of their move overseas.

\subsection{Practice theory}

Practice theory forms the second theory through which the findings of this study are analysed. Practice theory has most comprehensively been developed through the work of Schatzki (2002), Gherardi (2000) and Reckwitz (2002), among others, and is linked by the presence of core (and often contested) concepts rather than forming a single or unifying theory (Nicolini, 2012, p.1). While practice theories are connected through the premise that practices are central to social life, the diversity of approaches has led to the development of ontological and epistemological emphases as well as empirical and theoretical approaches to research. In centring upon exploring how practice is shaped, this study takes an ontological approach to research and draws upon Schatzki (2002, p.72) to define practices as constituted through an interwoven array of openended and spatiotemporally-dispersed activities that hang together.

The recognition that social structures only exist through the "performance of material activities" (Nicolini, 2012, p.3) illustrates that activity constitutes one of the key components of practice theory. From the perspective of this study, the realisation that these sayings and doings are continually unfolding illustrates how student information activities are produced through their engagement overseas and linked through organisational structures rather than constituting a pre-determined set of skills and dispositions that are the possession of a specific person. Practice theory also highlights that these activities are both embodied and materially-mediated. While practice theorists disagree on the role of material configurations, which are accorded "compositional significance" (Schatzki, 2010, p.132) rather than agency in this research, this study's recognition that practices are enacted through the use of "tools, technologies, bodies, actions and objects" (Fenwick, 2010, p.69) highlights the important role that nature and nonhuman organisms play within information literacy practices. Similarly, the recognition that language-students act and know through their body means that this study's practice theoretical perspective also reframes knowledge in terms of knowing or as a situated and unfolding activity rather than as an object that can be possessed (Gherardi, 2009, p.357). Lastly, practice theory's focus on activity centres the question of agency and power. While language-students constitute the "central motor" (Schatzki, 2002, p.189) to the ordering and perpetuation of social life, the recognition that social life is constituted through a site or a context (Schatzki, 2002) highlights how information literacy is simultaneously shaped by arrangements or set-ups of material objects that channel, prefigure and facilitate practices (Schatzki, 2012, p.16). In sum, practice theory's 
emphasis on the site of practice as well as what people do highlights how it forms a useful lens for this study of information literacy.

\section{Methodology and methods}

The study adopted a constructivist grounded theory methodological approach (Charmaz, 2014). The use of constructivist grounded theory, which draws attention to meaning as well as to multiple realities, moved the focus of this study beyond descriptions of skills and procedures to generate understanding that was situated in participant statements and activities. The emphasis on the co-construction of meaning further ensured that the study surfaced what was important to participants rather than just to the researcher. The use of constructivist grounded theory also foreshadowed the production of theoretical interpretation. Constituting interpretive theorising, which emphasises the construction of abstract understanding rather than decontextualised generalisations, as in positivist definitions of theory (Charmaz, 2014, p.229), constructivist grounded theory is emergent as well as centred on a reflexive consideration of meanings and actions. Theory that is generated from this study is consequently centred on participant realities as well as the conceptualisation of connections between the local setting and broader social structures.

\subsection{Research methods}

This study employed semi-structured interviews and photo-elicitation to generate and collect data. Semi-structured interviews provide an entry point to the practices and arrangements of a site (Schatzki, 2012, p.25) and were used in this study to gain an understanding of the ways in which research participants engaged with information during their time overseas. Each participant took part in two audio-recorded interviews, which took place shortly after their arrival and before their departure. Interview questions focused on exploring typical everyday activities in which information was expected to play an important role, including choosing a supermarket, opening a bank account and establishing leisure activities. Interviews were carried out through video-conference due to participants' varied locations around the world. These video interviews, which were marked by the overall absence of technological issues, provided access to activity and objects that would not have been visible within a face-to-face interview. Participant interviews lasted from between 24 minutes and 94 minutes, for an average of 56 minutes.

The study employed photo-elicitation to generate participant representations of their everyday information activities. The use of photo-elicitation, which parallels the emphasis within practice theory on embodied and materially-mediated activity, shifted the focus of research from a spoken description of information activities to the physical processes in which individuals engage (Hicks \& Lloyd, 2018). Photo-elicitation was employed after the first interview when participants were asked to use EthOS, a mobile ethnographic app, to capture photos of anything that had helped them to learn about or settle in overseas. A discussion about the ethics of taking photos for research purposes as well as the need to pay particular attention to appropriateness and personal safety within an unfamiliar environment was also carried out at this time. Images were reviewed by the participant and the researcher in the second interview and these discussions were integrated into study memos as well as being transcribed as part of the study's data. Participants took 160 photos with an average of about seven per participant.

Due to the financial costs, as well as the time and effort involved in gathering visual data, participants were offered a USD\$40 (GBP£25/ CAD\$50/ AUD\$50) iTunes, Amazon or Coles gift card in exchange for participation in this research. 


\subsection{Sample and recruitment}

The study's sample comprised 26 students who were learning a language other than English outside their home country. Participants were recruited from Australia, Canada, the United Kingdom and the United States and selected through a maximum variation purposive sampling strategy. Theoretical sampling helped to recruit additional respondents who were likely to have different experiences. While no language or country was ruled out, students whose placements lasted for less than three months were excluded to focus on interactions that went beyond a purely tourist experience. Participants were recruited through the informational website that the researcher sent to study abroad directors at 190 universities throughout North America, Australia and the UK as well as to librarian and language education listservs.

All but one of the 26 participants were undergraduates, with the other participant having recently graduated. Most participants came from the UK (12, with nine from England, two from Wales, and one from Scotland) or from the US (eight), with three each from Australia and Canada. In terms of their location overseas, participants were studying eight European and Asian languages (French, German, Icelandic, Italian, Japanese, Mandarin, Russian, Spanish) within a total of 14 countries in Europe, the Americas, Asia, Eurasia and Africa in a variety of urban and rural settings. In terms of occupation, most participants spent their time abroad studying (17), with nine students engaged in a work or volunteer placement.

\subsection{Data analysis}

This study employed grounded theory and situational analysis methods. Constructivist grounded theory methods of analysis, which are centred on constant comparison, enabled the establishment of the information activities that formed the basis of the final grounded theory while ensuring that these activities emerged from participant data rather than from pre-existing theories (Charmaz, 2014, p.115). Extensive memo-writing accompanied this process to raise data to analytical significance and establishing category saturation. The use of situational analysis methods, which mirrored the practice theoretical emphasis on the site as the context in which social life transpires (Schatzki, 2002), facilitated a visual mapping of the data as well as an exploration of the connections between the key "elements, materialities, discourses, structures, and conditions that characterize the situation of inquiry" (Clarke, 2005, p.xxii). Situational analysis further drew attention to unarticulated concepts or the "sites of silence" within the data (Clarke, 2005, p.85).

\subsection{Limitations}

This study's use of video interviews meant that it was subject to several limitations, including a reliance on retrospective narratives as well as a lack of face-to-face engagement. The employment of photo-elicitation further ran the risk of over-emphasising the visual aspects of this research while asking participants to take photographs of information may have proved to be complex or confusing. The narrowness of the sample provided an additional limitation; the nature of higher education meant that most potential participants were studying French, German and Spanish in Europe. To counter these limitations, the researcher worked to build rapport with participants while additionally using the second interview to explore the meaning that participants attached to photographs. Participants were also given the opportunity to critique the emerging analysis while theoretical sampling helped to recruit more diverse respondents. 


\section{Findings}

Data produced from this study are used to explore language-students' information literacy practices. This analysis, which examines how language-students construct their new information landscapes as they transition into their host communities, identifies seven information activities that configure two categories, Calibrating and Repositioning, as represented by Figure 1. These categories subsequently establish the study's overarching theme, Mitigating Risk, which constitutes the grounded theory. Participant quotes will be used to contextualise these findings. Participant are referred to either by their own name or a pseudonym in accordance with their wishes.

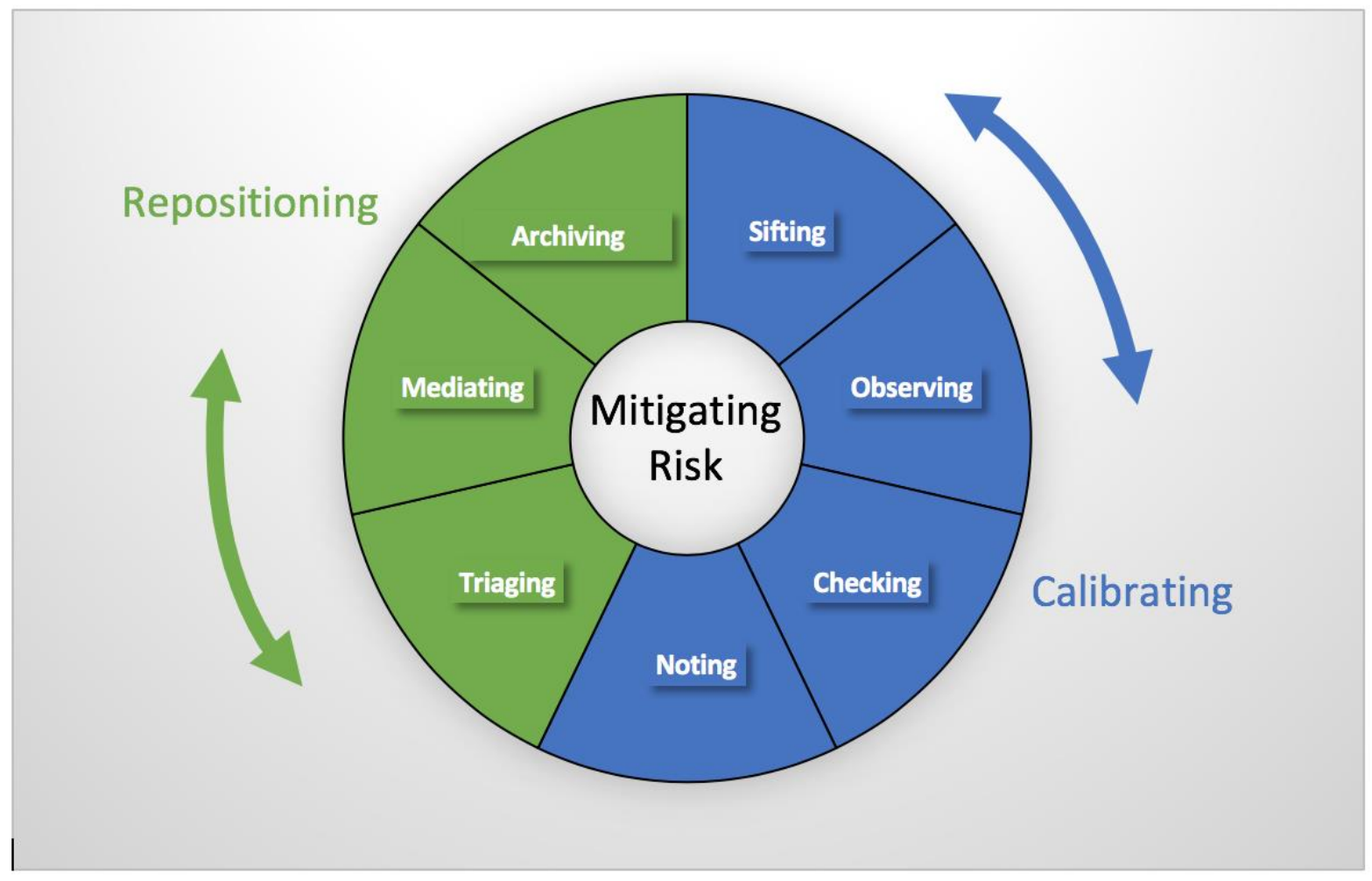

Figure 1: Information activities during residence abroad

\subsection{The information environment}

As students start to engage overseas, they encounter a range of new information environments and challenges that tax their ability to situate themselves within their new setting. New responsibilities, which range from the obligation to comply with the legal and institutional requirements that govern their stay abroad to the need to establish basic requirements, such as finding accommodation, are additionally intensified by the time-sensitive nature of each demand. In turn, the need to rebuild understanding about local services, including setting up telephone or internet access as well as working out how to use transport systems, increases the calls on students' time and energy even as they are forced to mediate local idiosyncrasies such as new currencies and different weather systems. Recognising that this period is both exciting and frustrating, language-students engage in various information activities to mediate their participation abroad. 


\subsection{Calibrating}

Calibrating, which refers to the adjustments that language-students make through comparison to knowledgeable others, forms one of the two primary ways in which students start to mediate their uncertainty within a new information environment. Forming a way to build and evaluate understanding against the standards of local practice, calibrating enables students to start mapping and orienting themselves to their new context. One of the most obvious models of practice against whom language-students calibrate their activity is the local or native speaker, whose highly desirable linguistic and cultural fluency means that they are immediately associated with expertise as well as with insider knowledge (cf. Mansour \& Francke, 2017). Locals and native speakers, who are both accessible and members of a socially approved group in which students wish to participate (Hultgren, 2013, p.279), are also valued for their ability to make the social practices that structure local performance visible. Engagement in the information activity of observing, for example, helps Genevieve, an American studying in Russia, to recognise the tacit and nuanced understandings that underscore the activities of a local religious community:

I would kind of stand in the back of the church and watch what everyone else was doing and by the end of the service when we would go up for communion, at that point I was much more like familiar, I would get to the end of the line, so I could do whatever anyone else did.

These interactions between experienced and newcomer bodies, which constitute what Lave and Wenger (1991) label as legitimate peripheral participation, also signal what not to do within a new setting. Laura, who is a British student volunteering in Bolivia, realises that video chatting is not permitted in her favourite café through observing a waiter's body language:

They give you evils sometimes, I haven't been told off, I think it's because since then I try and be really subtle, so if the waiter comes, I normally like, stop talking or just gesture, so it's fine.

Forming a type of attunement where experienced and inexperienced bodies act in tandem rather than in opposition to each other, bodily interactions have also been noted as facilitating refugees' engagement within a new setting (Lloyd et al., 2013).

At the same time, authority is not just limited to these more obviously 'expert' or institutionally sanctioned sources, as McKenzie (2003, p.283) notes in her study of women who are pregnant with twins. Students who have returned from their time abroad constitute an equally valid authority for new language-students, both because they represent knowledge derived from experience and because they demonstrate that there is a scope for the "mature practice of what they are learning to do" (Lave \& Wenger, 1991, p.110). In engaging in the information activity of sifting, Stuart, who is British and studying in China, illustrates how combing through the recommendations and advice of recently returned students helps him to build an awareness of what to expect from his upcoming trip:

I had a couple of meetings with people who had been here before, the two people I know. And so, the two of us who came, from [his university], went to the pub with them and 
talked to them about what to expect, what to bring, what to be worried about, that kind of thing.

An engagement with returned students enables current language-students to add details to the picture that they are creating of their new location while further recognising and legitimising their identity as language-students who will be travelling abroad. Interaction also builds student confidence as they start to situate themselves within a new environment, as Kamila, a Canadian student studying in France, illustrates:

Like, you see numbers, you see all the information, ok, that's cool and but then seeing a person, a real live person who did it, went there, saw things, went through all the problems, and that makes it more real, and that makes you more excited!

The important motivational role that people who are in similar circumstances play within transition is also noted in studies of health (e.g. Lloyd, Bonner \& Dawson Rose, 2014; Veinot, 2009) and migration information practices (Caidi, Allard \& Quirke, 2010, p.507).

Knowledgeable others also enable language-students to calibrate their own performance within a new context. In measuring their activity against the performance of experienced others, language-students directly and indirectly pursue the feedback that will contribute to their understanding about the shape of competent activity within a setting. With no prior experience to serve as a template against which she can gauge her understanding of local practices, Luan, who is a British student working in Belgium, engages in the information activity of checking to mediate the potential of making financially and temporally costly errors:

I used to ask the bus driver just to make sure, because I didn't want to end up on the other side of Brussels, but I used to ask him like, 'this is definitely going to this place, isn't it?', kind of thing.

In helping to validate both her interpretation of knowledgeable activity and her own performance within this setting, Luan's question represents an attempt to calibrate her activity or to corroborate whether her actions are considered valid in the eyes of a local as well as forming a query about the accuracy of the information that she has found.

In turn, students engage in the information activity of noting as a way to support calibrating over time. The contingency of nuanced information as well as its typical visual or aural format means that it can be hard to remember and recreate. Noting stabilises the ephemerality of this information by helping students to translate it into a more permanent notation, as Genevieve and Helen, a British student working in Guadeloupe, demonstrate: 
Our programme had pointed [a church] out while we were getting a tour of Moscow... so, I took a picture of their hours, and just walking around I would notice a church, I would go up to it and see if they had their hours posted anywhere, and so I have like, seven churches' hours on my phone right now. (Genevieve)

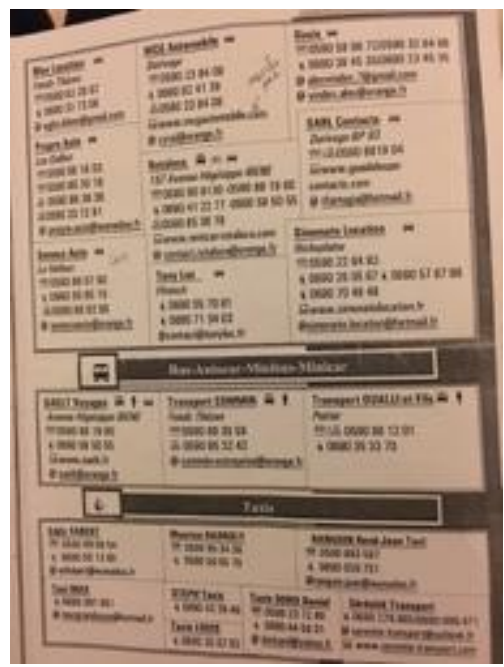

Figure 2: Helen's annotated list of transport options

Genevieve's use of photos highlights how calibrating is coordinated through the creation of multimodal and material objects. Her comments also illustrate the important role that the mobile phone, which has been seen to support the transition to university (McEwen \& Caidi, 2013), plays within students' time overseas. Connecting students' past, present and future interactions overseas, phones provide a convenient way for language-students to maintain a reliable record of performance within a new space as well as to reproduce this activity consistently over time.

\subsection{Repositioning}

Repositioning, which refers to how language-students situate themselves within and in relation to an information environment, forms the second of the two ways in which students start to mediate their uncertainty overseas. Centred on the management of their participation within a new setting, repositioning forms the means through which students negotiate the barriers that impact their engagement overseas while also validating their growing confidence and expertise within a setting. One of the most important reasons for which students work to reposition themselves within their information environment is to maintain their access to the social and material opportunities of their setting. Student recognition that the way they look and sound impacts their opportunities to participate within a new information environment means that their information activities become directed towards re-establishing their legitimacy within a new setting. In purposefully channelling his attention towards expatriate websites rather than to the advice his host university provides, Alex S., who is a British student studying in Germany, engages in the information activity of triaging to reposition himself within the information landscape of a (more desirable) long-term resident professional rather than that of a student:

I've also used just websites for expats in Berlin I just found on Google and those were really helpful, other people who'd been in similar situations could speak less German than I could, very clear instructions on what to do to register. 
In illustrating that students purposefully reject potentially useful information to direct the way in which they are perceived within a new setting, Alex S.'s actions are reminiscent of how newly arrived migrants would refrain from using paper maps that they perceived as tourist-like to find their way around New York City (Lingel, 2014, p.758). The recognition that individuals define themselves through the practices in which they do not engage as well as the ones in which they do (Wenger, 1998, p.164) demonstrates how repositioning also marks a transition from individual to collective knowing as students start to think of themselves and their activities in terms of their connections and relations to others.

Repositioning also forms a way for students to deal with the stress that is produced through their engagement overseas as they are forced to deal with competing demands on their time and energy. Students regulate their continued engagement within a new information environment through recognising and then repositioning themselves in relation to the emotional impact of their time overseas. Having latched onto the first functional route to work that she had found, Evelyn, who is a British student working in Austria, protects her fragile understanding of her new situation by triaging information or deprioritising her exploration of more efficient transportation options until she has the capacity to plan an alternative journey:

There were multiple opportunities to get to work, but I think I visited work before I started my internship just to say 'Hi,' and took one specific route and then I stuck to that for about two weeks.

Helping her to create a buffer for activity, Evelyn's purposeful response to the uncertainty that is produced within a new situation forms an assertion of agency amidst the stress and anxiety of a new situation rather than a complete disconnection from her host society. Students' social relationships also help them to deal with the stresses and strains that are produced through their participation within a new information environment. Genevieve and Jemma, who is a British student working in France, engage in the information activity of mediating to share information about their experiences with friends and family back home and build the emotional support they need to sustain their engagement overseas:

I Skype with my mom usually once a week and just kind of update her on the things moms care about like how life has been. (Genevieve)

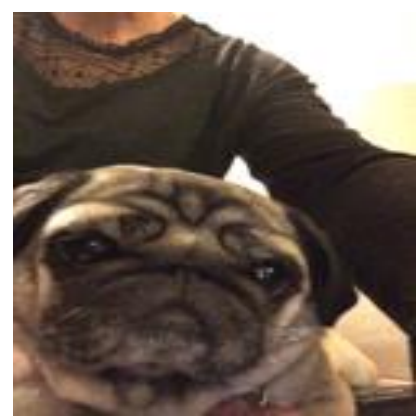

Figure 3: Jemma's FaceTime with family

Illustrating how the common activity of sharing information becomes more resonant when students are deprived of easily accessible support systems, mediating can also be interpreted as students' attempt to ensure that they are not forgotten about as they move multiple time zones away. Occurring within the general flow of everyday conversation rather than forming a purposeful information activity, mediating information has also been seen to build vital emotional connections for people with health issues (Lloyd et al., 2014, Veinot, 2009). 
Increasing confidence also means that students reposition themselves in terms of their own growing expertise and competence within a new setting. Students' recognition of their own learning and development validates the understanding that they have constructed through their embodied engagement overseas and helps them to reconfigure the ways in which they see and portray themselves within a new context. In mediating transport information to co-located friends, Laura highlights how their acknowledgment of her proficiency enables her to reposition herself in relation to her new setting:

So, I'm like, an expert in all the buses, so we normally meet so I can show them what bus we need to take.

Laura's growing awareness of and alignment with collective ways of knowing demonstrates how student participation within a new setting can be empowering as well as disempowering (Lave $\&$ Wenger, 1991, p.36). At the same time, the recognition that her growing expertise accords her the power to shape her local context raises a number of questions about what information she can and does share with others.

The tangibility of material artefacts means that engagement in the information activity of archiving further helps students to reposition themselves as experienced within a new setting. The creation of memory objects such as souvenirs and journals helps students to mark a significant period in their life while the irreproducibility of the mundane ephemera that students collect, which includes tickets and brochures, corroborates both their existence and their embodied expertise. Fiona, who is a Canadian student studying in France, demonstrates her authority within a setting by transforming the unfamiliarity of her local information environment into something that she can both hold and remove:

I just go to the beach and put a bit of sand in a Ziploc bag and label it and when I'm home, I put the sand in a little Mason jar.

Providing a way to revivify student time overseas, archiving also reinforces students' identities of expertise through the creation of a personal narrative or a stabilising sense of continuity about and within their lives; as Bowker (2005, p.9) points out, documentation enables "both the creation of a continuous, useful past and the transmission sub rosa of information, stories, and practices from our wild, discontinuous, ever-changing past." In turn, these artefacts help students to reinforce their credibility over time as they transition back home.

\section{Mitigating risk: A grounded theory}

Calibrating and repositioning were subsequently drawn together to produce the overarching category of mitigating risk. Findings were then conceptualised through the lens of the study's theoretical framework as well as other relevant theoretical constructs to produce the grounded theory of mitigating risk, as represented by Figure 4. The emphasis on interpretative sensitivity and the production of situated knowledge, which Charmaz (2014) positions at the heart of constructivist grounded theory, further illustrates how mitigating risk moves beyond a descriptive or explanatory rendering of the data to articulate emerging theoretical claims. More specifically, the grounded theory of mitigating risk states that the risks that are produced through participation in a new information environment catalyse the enactment of the information literacy practices that mediate student transition from acting like to becoming a language-learner 
overseas. Painting a rich picture of how newcomers build understanding within new information environments, the grounded theory of mitigating risk has a number of implications for our understanding of both transition and information literacy.

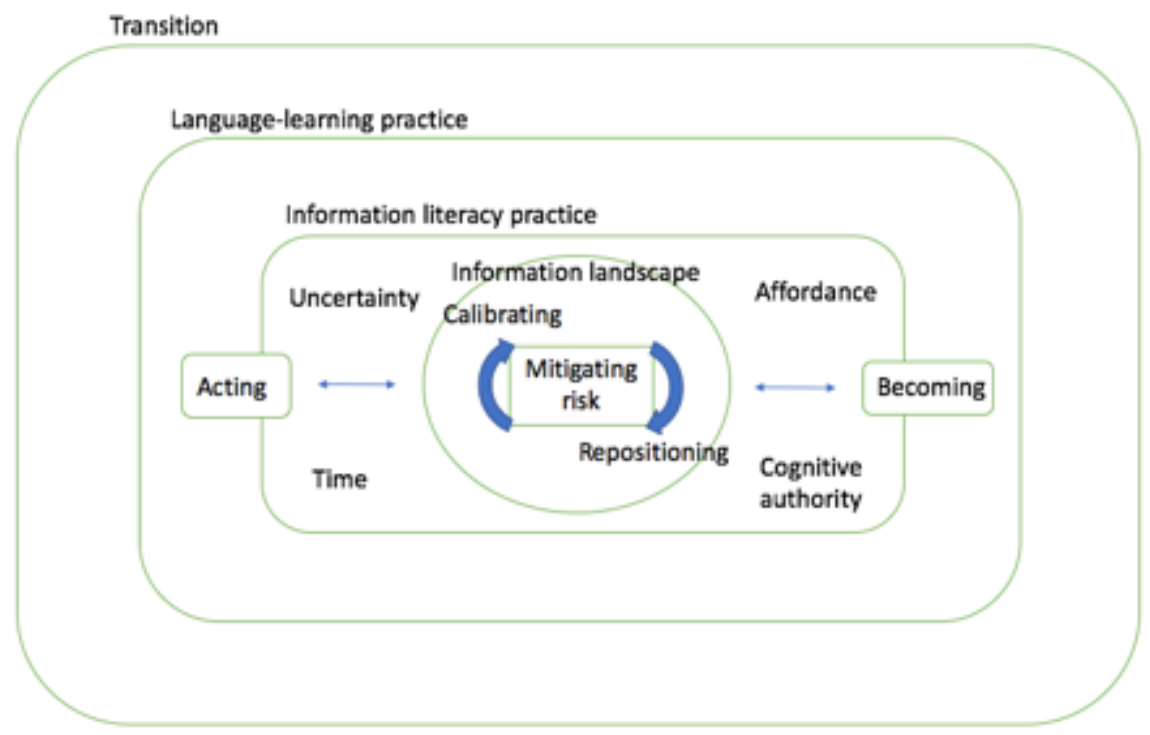

Figure 4: The grounded theory of mitigating risk

Risk forms the first major concept within the grounded theory of mitigating risk. As students participate within the activities of their new setting, the unfamiliarity of the new information environment and the loss of support structures means that their engagement overseas produces considerable uncertainty (Kuhlthau, 1993). This uncertainty is further intensified by the finite duration of students' stay abroad as well as by the temporal shape of their engagement in practice (cf. Schatzki, 2012). Uncertainty and time subsequently coalesce to create a series of risks that threaten student engagement within their new setting, including threats to students' physical safety within a new location, pressures of financial hardship due to strained budgets, and academic risk, as illustrated by the danger of failing to improve their language ability during this time overseas. Risk has typically been positioned as an objective hazard within an increasingly risk-averse society (Beck, 1992). However, the recognition that the risks that threaten students' stays overseas are produced through the meaning and significance that this time holds in their lives illustrates how both risk and students' response to risk are contextualised as well as produced through their engagement overseas. The related theoretical construct of edgework (Lyng, 1990), which emerged through studies of voluntary risk-taking, further illustrates how the risk that structures student time overseas is mediated through preparation and the development of expertise as well as students' increasing sense of control over their body rather than uniquely forming something to be avoided. The recognition that these risks can facilitate development and growth draws attention to the emergence of student agency as well as to its curtailment.

The potential impact of these risks consequently catalyses the enactment of information literacy practices as students engage in calibrating and repositioning to mitigate these threats to their stay overseas. The enactment of information literacy practices helps students to mitigate risk by connecting them to the sources of information that will allow them to develop situated 
and nuanced understandings of their new setting. More specifically, calibrating illustrates how students rely on knowledgeable others to rebuild knowing within a new setting. Constituting the people who students position as trustworthy and credible, these cognitive authorities (Wilson,1983) help students to mediate risk by enabling them to identify what constitutes competence as well as knowledge within a new setting. Cognitive authorities further facilitate knowing by drawing students in from the periphery of practice (Lave \& Wenger, 1991) and creating a route through which student bodies become a site of information for others (cf. Schatzki, 1997, p.44). In contrast, repositioning demonstrates how students build knowing through learning to perceive the affordances of a site (Billett, 2001) or the opportunities that a community offers to interact with information. The recognition that these opportunities are often restricted on the basis of assumed competence illustrates how students mitigate risk through negotiating their ongoing access to information that is both valued within a community and only available through engagement in practice. The active role that students play in maintaining their engagement within a new information environment also illustrates how information literacy practices are shaped through the complexity of social interaction rather than merely forming a process of reproduction and socialisation.

The emphasis on the development of intersubjective understanding consequently illustrates how the enactment of information literacy practices mediates students' transition from acting like a language-learner to becoming a language-learner within the structure of residence abroad. While students have considerable experience in the classroom, their identity as a language-learner tends to have been developed in relation to an academic information landscape rather than to the informal and vernacular sources of information that structure local ways of knowing whilst they are overseas. Information literacy practices enable students to mediate the transition from the classroom to everyday language-learning settings by helping them to situate themselves in relation to their new role and responsibilities and to reconfigure their identity around local and intersubjective understandings of practice. The transition from acting to becoming, which is seen most clearly through the changes that students make to the way that they dress and talk as well as through their attempts to forget language-learning strategies that have previously been successful for them, is further characterised as a move from engaging with information to learn about practice to engaging with information to enhance practice (Lloyd, 2006, p.576) as students become increasingly engaged within their new setting. At the same time, the recognition that transition unfurls in relation to complex social structures highlights how student becoming is both fluid and dynamic rather than forming a chronological and linear pathway (Fenwick, 2013, p.364). Information literacy subsequently becomes positioned as a transformative learning practice that scaffolds student engagement in the challenges and opportunities of change.

\section{Discussion}

The grounded theory of mitigating risk demonstrates that the pressures that are produced during residence abroad catalyse the enactment of the information literacy practices that subsequently mediate student transition within a new setting. The recognition that this period of change forms a time of upheaval as well as opportunity means that mitigating risk has various implications for understandings about both information literacy and transition.

From an information literacy perspective, the grounded theory of mitigating risk illustrates that, as a practice, information literacy is enacted or takes place "in the act" (Mol, 2002, p.33) rather than achieved through the performance of institutionally-approved individual 
skills. The emphasis on enactment highlights the continually unfolding shape of information literacy practice as well as the active role that learners play in building understanding within a new information environment. The recognition that information activities bring people into being (Lloyd, 2017, p.95) further moves the emphasis of information literacy from what is learnt to the resulting "change in person" (Lave \& Wenger, 1991, p.51) and the important role that subjectivity plays in the development of knowing. At the same time, the presence of risk also highlights how the enactment of information literacy practice is also structured through students' temporal goals and motivations for this period or what Schatzki $(2012$, p.18) refers to as "the past-present-future dimensionality of activity." Illustrating how student information landscapes are constructed through a reflexive engagement in the present as well as through what mattered to them in the past and what they want to achieve in the future, the theory of mitigating risk broadens awareness about the shape of student engagement with information by demonstrating how information literacy practices are both socioculturally and temporally-mediated.

The grounded theory of mitigating risk also extends understanding about the situated shape of information literacy practices. The recognition that students use mobile phones and memory objects, amongst other items, to structure their information activities whilst they are overseas illustrates the important role that everyday material artefacts as well as more specialised information resources play in facilitating the development of knowing within an unfamiliar information environment. Similarly, the emphasis on preparation for the future demonstrates how information literacy depends on the coordination and synchronisation of activity across time as well as information that only comes from being present in a setting. The theory of mitigating risk also develops understanding about the means through which local social mediators shape information literacy practices. The recognition that social mediators help students to assess their own performance within a new situation, as illustrated by calibrating, illustrates how information literacy centres on the alignment of activity as well as the building of connection to local sources of knowledge. The support that students receive from friends and family whilst they are overseas further illustrates how information literacy is shaped in relation to the emotional assistance that helps students to maintain their engagement overseas, as both Lloyd et al (2014) and Veinot (2009) found in their studies of chronically ill patients.

From the perspective of transition, the grounded theory of mitigating risk positions change as a period of upheaval in which the enactment of information literacy practices facilitates the building of meaning within a new context. The emphasis on students' growing knowledgeability within a new setting reframes transition as a "critically intensive learning period" (Kilminster, Zukas, Quinton \& Roberts, 2010, p.556) rather than uniquely constituting a time of discontinuity and stress. Importantly, the recognition that students continue refining how they engage with and situate themselves in relation to legitimised ways of knowing means that transition is also positioned as a cyclical process that is extended over time rather than as the attainment of normative expectations of success (cf. Fenwick, 2013, p.362). In centring on redefinition and renewal, mitigating risk further highlights the active role that language-students play in mediating transition. Nursing transitions theory (Meleis et al., 2000) has tended to position individuals as passive recipients of expert assistance during transition. However, the understanding that students reflect upon their actions and resist the ways in which they are positioned by others illustrates how transition is produced through students' active participation within their new setting rather than occurring to people who have little control over their destiny.

At the same time, the grounded theory of mitigating risk highlights that transition plays out through rather than in isolation from the unfolding complexity of social interaction. While 
student preparation for change helps them to manage and legitimise their expectations (cf. Meleis et al., 2000, p.22), the inseparable nature of learning, practice and performance (Kilminster et al., 2010) means that transition is shaped through the community and social conditions of a setting rather than uniquely in relation to students' individual motivations for this time overseas. These social structures can limit student possibilities for action by isolating them from their new information environments. Conversely, the actions of locals as well as the set-ups of material objects that prefigure practices (Schatzki, 2012, p.16) can also facilitate the development of knowing by channelling student engagement towards more supportive activities. Echoing the learning dynamics that are found in the concept of legitimate peripheral participation (Lave \& Wenger, 1991), mitigating risk illustrates how transition is marked by tension as well as by the development of intersubjective understanding. The recognition that these community structures become enmeshed within students' own increasingly knowledgeable performance within a setting further highlights the complex interdependency of social relations.

\section{Conclusion}

This paper has presented the grounded theory of mitigating risk, which emerged through an extended exploration of the information literacy practices of English-speaking students who were learning a language overseas. The theory of mitigating risk illustrates how engagement overseas produces academic, financial and physical pressures that are mediated through students' increasingly knowledgeable engagement with the information sources that are valued within their new setting. The enactment of information literacy practices subsequently facilitates transition as students rebuild their language-learning identity through and in relation to their new setting. The recognition that student time overseas is structured through the challenges and opportunities that risk presents illustrates how the theory of mitigating risk develops understanding about the complexity of building meaning within culturally different contexts. The important role that information plays in facilitating the development of subjectivity further demonstrates how the theory of mitigating risk adds another dimension to literature that positions transition in terms of becoming (Gale \& Parker, 2014).

The emphasis on student development means that the grounded theory of mitigating risk also has a number of practical implications for librarians, study-abroad coordinators and language-educators, as a separate paper explores at length (Hicks, 2019). The recognition that students are negotiating complex transitional processes sets the scene for the design of educational interventions that recognise the fluid and generative possibilities of this period while the importance of supportive connections further illustrates the need for learning opportunities that facilitate interaction. Future studies should continue to explore the shape and impact of transition within other contexts as well as the role that risk plays during this time, including within non-academic contexts and in relation to engagement in stigmatised or high-stress activities. Transition impacts every area of social life and it is important that LIS research continues to examine the key role that information practices plays in mediating these complex processes of change.

\section{References}

Association of College and Research Libraries (ACRL) (2000). Information literacy competency standards for higher education. Retrieved from www.ala.org/ala/acrl/acrlstandards/standards.pdf

Baldwin, J. and Hunt, S. (2002), "Information-seeking behavior in intercultural and intergroup 
communication", Human Communication Research, Vol.28 No.2, pp.272-286.

Bateson, G. (1972), Steps to an Ecology of Mind: Collected Essays in Anthropology, Psychiatry, Evolution, and Epistemology, Chicago: University of Chicago Press.

Beck, U. (1992), Risk Society: Towards a New Modernity, London: SAGE.

Bent, M.J. (2008), Perceptions of information literacy in the transition into higher education report. National Teaching Fellowship Project Report, 1-67. Retrieved from http://www.mendeley.com/research/perceptions-information-literacy-transition- highereducation-report-2008/

Billett, S. (2001), "Learning through work: Workplace affordances and individual engagement", Journal of Workplace Learning, Vol.13 No.5, pp.209-214.

Blumer, H. (1969), Symbolic Interactionism: Perspective and Method, Englewood Cliffs, NJ: Prentice-Hall.

Bordonaro, K. (2006), "Language learning in the library: An exploratory study of ESL students", Journal of Academic Librarianship, Vol.32 No.5, pp.518-526.

Bowker, G.C. (2005), Memory Practices in the Sciences, Cambridge, MA: MIT Press.

Burhanna, K.J. (2013). Informed transitions: Libraries supporting the high school to college transition. Santa Barbara, CA: Libraries Unlimited.

Burr, V. (1995), An Introduction to Social Constructionism, London: Routledge.

Caidi, N., Allard, D., and Quirke, L. (2010), "Information practices of immigrants", Annual Review of Information Science and Technology, Vol.44 No.1, pp.491-531.

Charmaz, K. (2014), Constructing Grounded Theory, London: SAGE.

Clarke, A. (2005), Situational Analysis: Grounded Theory after the Postmodern Turn, Thousand Oaks, CA: SAGE.

Cooper, L., \& Hughes, H. (2017), “First-year international graduate students' transition to using a United States university library", IFLA journal, Vol.43 no.4, pp.361-378.

Deakin, H. (2012), Erasmus Student Work Placement Mobility: A UK Perspective, Loughborough University, UK.

Dockett, S., \& Perry, B. (2007), Transitions to school: Perceptions, expectations and experiences. Sydney, NSW: UNSW Press.

Ecclestone, K., Biesta, G., \& Hughes, M. (2010). Transitions in the lifecourse: The role of identity, agency and structure. In: K. Ecclestone, G. Biesta \& M. Hughes, (Eds.), Transitions and learning through the lifecourse (pp.1-15). Abingdon: Routledge.

Fenwick, T. (2013), "Understanding transitions in professional practice and learning: Towards new questions for research", Journal of Workplace Learning, Vol.25 No.6, pp.352-367.

Fenwick, T. (2010), "Re-thinking the "thing" sociomaterial approaches to understanding and researching learning in work", Journal of Workplace Learning, Vol.22 No.1/2, pp.104-116.

Fine, G.A. (1993), "The sad demise, mysterious disappearance, and glorious triumph of symbolic interactionism", Annual Review of Sociology, Vol.19, pp.61-87.

Gale, T., \& Parker, S. (2014), "Navigating change: a typology of student transition in higher Education", Studies in Higher Education, Vol.39 No.5, pp.734-753.

Gergen, K. and Gergen, M. (2008), "Social constructionism”, in Given, L.M. (Ed.), The Sage Encyclopedia of Qualitative Research Methods, Thousand Oaks, CA: SAGE, pp.816-820.

Gherardi, S. (2009), "Knowing and learning in practice-based studies: An introduction", The Learning Organization, Vol.16 No.5, pp.352-359. 
Gherardi, S. (2000), "Practice-based theorizing on learning and knowing in organizations: An introduction," Organization Vol.7 No.2, pp.211-23.

Gilhooly, D. and Lee, E. (2014), "The role of digital literacy practices on refugee resettlement", Journal of Adolescent and Adult Literacy, Vol.57 No.5, pp.387-396.

Goodall, K.T. (2013), Becoming Informed: A Grounded Theory of How Older Greek and Italian Migrants to South Australia Find Everyday Information, Flinders University, Australia.

Han, J. (2012), "Information literacy challenges for Chinese PhD students in Australia: A biographical study”, Journal of Information Literacy, Vol.6 No.1, pp.3-17.

Hicks, A. (2019). Building intercultural teachers: Designing information literacy instruction opportunities for increasingly international populations. Journal of Academic Librarianship, 45(2), 146-152.

Hicks, A. (2014), "Bilingual workplaces: Integrating cultural approaches to information literacy into foreign language educational practices", Journal of Information Literacy, Vol.8 No.1, pp.21-41.

Hicks, A., and Lloyd, A. (2016), "It takes a community to build a framework: Information literacy within intercultural settings", Journal of Information Science, Vol.42 No.3, pp.334-343.

Hicks, A. and Lloyd, A. (2018), "Seeing information: Visual methods as entry points to information practices", Journal of Librarianship and Information Science, Vol.50 No.3, pp.229-238.

Hughes H. (2013), "International students using online information resources to learn: complex experience and learning needs", Journal of Further and Higher Education, Vol.37 No.1, pp.126-146.

Hughes, H., Cooper, L., Flierl, M., Somerville, M. M., \& Chaudhary, N. (2018), "The role of the university library in supporting international student transition: Insights from an Australian-American case study," The Journal of Academic Librarianship, Vol.44 No.5, pp.582-594.

Hultgren, F. (2013), “The stranger's tale: Information seeking as an outsider activity”, Journal of Documentation, Vol.69 No.2, pp.275-294.

Hyldegård, J.S. and Hertzum, M. (2016), "Coping with private and academic information needs abroad: An exploratory study of international students”, In ASIS\&T Annual Meeting 2016.

Ishimura, Y. (2013). "Information behavior and Japanese students: How can an understanding of the research process lead to better information literacy?" Public Services Quarterly, Vol. 9 No.1, pp.20-33. doi:10.1080/15228959.2013.758977

Ivins, T., Copenhaver, K., \& Koclanes, A. (2017). "Adult transitional theory and transfer shock in higher education: Practices from the literature", Reference Services Review, Vol.45 No.2, pp.244-257. doi:10.1108/RSR-08-2016-0048.

Jeong, W. (2004), "Unbreakable ethnic bonds: Information-seeking behavior of Korean graduate students in the United States", Library and Information Science Research, Vol.26 No.3, pp.384-400. doi:10.1016/j.lisr.2004.04.001

Jones, J., Fleischer, S., McNair, A., \& Masika, R. (2018), “The International Foundation Year and first year transition: building capital, evolving habitus, developing belonging, preparing for success", Teaching in Higher Education, 1-16.

Kilminster, S., Zukas, M., Quinton, N., and Roberts, T. (2010), "Learning practice? Exploring the links between transitions and medical performance", Journal of Health Organization 
and Management, Vol.24 No.6, pp.556-570.

Kralik, D., Visentin, K., and van Loon, A. (2006), "Transition: A literature review”, Journal of Advanced Nursing, Vol.55 No.3, pp.320-329.

Kuhlthau, C.C. (1993), “A principle of uncertainty for information seeking”, Journal of Documentation, Vol.49 No.4, pp.339-355.

Lave, J., and Wenger, E. (1991), Situated Learning: Legitimate Peripheral Participation, Cambridge: Cambridge University Press.

Lingel, J. (2014), "Information as performance: Mobile technology, city streets and the antiTourist", In iConference Proceedings, 755-762.

Lloyd, A. (2006), "Information literacy landscapes: An emerging picture," Journal of Documentation, Vol.62 No.5, pp.570-583.

Lloyd, A. (2007), "Learning to put out the red stuff: Becoming information literate through discursive practice", Library Quarterly, Vol.77 No.2, pp.181-198.

Lloyd, A. (2015), "Stranger in a strange land: Enabling information resilience in resettlement landscapes", Journal of Documentation, Vol.71 No.5. pp.1029-1042.

Lloyd, A. (2017), "Information literacy and literacies of information: A mid-range theory and model", Journal of Information Literacy, Vol.11 No.1, pp.91-105.

Lloyd, A., Bonner, A., and Dawson-Rose, C. (2014), “The health information practices of people living with chronic health conditions: Implications for health literacy", Journal of Librarianship and Information Science, Vol.46 No.3, pp.207-216.

Lloyd, A., Kennan, M.A., Thompson, K., and Qayyum, A. (2013), "Connecting with new information landscapes: Information literacy practices of refugees", Journal of Documentation, Vol.69 No.1, pp.121-144

Lloyd, A., \& Somerville, M. (2006), "Working information," Journal of Workplace Learning, Vol.18 No.3, pp.186-198. doi:10.1108/13665620610654603

Lloyd, A. and Wilkinson, J. (2016), "Knowing and learning in everyday spaces (KALiEds): Mapping the information landscape of refugee youth learning in everyday spaces", Journal of Information Science, Vol.42 No.3, pp.300-312.

Lobburi, P. (2012), "Maintaining long-distance friendships: Communication practices For seeking and providing social support across geographic divides", Journal of International Education Research, Vol.8 No.2, pp.125-135.

Lyng, S. (1990), "Edgework: A social psychological analysis of voluntary risk taking", American Journal of Sociology, Vol.95 No.4, pp.851-886.

Mansour, A., and Francke, H. (2017), "Credibility assessments of everyday life information on Facebook: A sociocultural investigation of a group of mothers", Information Research, Vol.22 No.2.

Martin, F. and Rizvi, F. (2014), "Making Melbourne: Digital connectivity and international students' experience of locality", Media, Culture \& Society, Vol.36 No.7, pp.1016-1031.

McEwen, R., and Caidi, N. (2013), "Texting home: Examining the mobile phone practices of student newcomers to Toronto", In Proceedings of the Annual Conference of CAIS/Actes du congrès annuel de l'ACSI.

McKenzie, P.J. (2003), "Justifying cognitive authority decisions: Discursive strategies of information seekers", The Library Quarterly, Vol.73 No.3, pp.261-288.

Mehra, B. (2007), "Affective factors in information seeking during the cross-cultural learning process of international doctoral students in Library and Information Science education", In Nahl, D., and Bilal, D. (Eds.), Information and Emotion: The Emergent Affective 
Paradigm in Information Behavior Research and Theory (pp.279-301). Medford, NJ: Information Today.

Meleis, A.I., Sawyer, L., Messias, D.H., Im, E.-O., and Schumacher, K. (2000), "Experiencing transitions: An emerging middle-range theory", Advanced Nursing Science, Vol.23 No.1, pp.12-28.

Mikal, J. (2011), "When social support fits into your luggage: Online support seeking and its effects on the traditional study abroad experience", Frontiers: The Interdisciplinary Journal of Study Abroad, Vol.21, pp.17-40.

Mol, A. (2002), The Body Multiple: Ontology in Medical Practice, Durham, NC: Duke University Press.

Moring, C. (2012). Newcomer information practice: Negotiations on information seeking in and across communities of practice. Human IT: Journal for Information Technology Studies as a Human Science, 11(2). Retrieved from https://humanit.hb.se/article/view/66

Nelson, E. (2017), "Information literacy needs of community college students in transition: a literature review," Reference Services Review, Vol.45 No.2, pp.278-285.

Nicolini, D. (2012), Practice Theory, Work, and Organization: An Introduction, Oxford: Oxford University Press.

Oh, C.Y., Butler, B., \& Lee, M. (2014), "Information behavior of international students settling in an unfamiliar geo-spatial environment", In Proceedings of the 77th ASIS\&T Annual Meeting (pp.1-11). Retrieved from https://asist.org/asist2014/proceedings/submissions/papers/182paper.pdf

Perry, B., Dockett, S., \& Petriwskyj, A. (2013), Transitions to School-International Research, Policy and Practice. Springer Science \& Business Media.

Reckwitz, A. (2002), "Toward a theory of social practices: A development in culturalist theorizing," European Journal of Social Theory, Vol.5 No.2, pp.243-263.

Reed, K. (2009), Information Hippies, Google-Fu Masters, and Other Volunteer Tourists in Thailand: Information Behaviour in the Liminoid, University of Alberta, Canada.

Richards, W. (2015), Need to Know: Information Literacy, Refugee Resettlement and the Return from the State of Exception, University of Southern Queensland, Australia.

Rogoff, B. (2003). The Cultural Nature of Human Development. Oxford: Oxford University Press.

Schatzki, T. (1997), "Practices and actions: A Wittgensteinian critique of Bourdieu and Giddens", Philosophy of the Social Sciences, Vol.27 No.3, pp.283-308.

Schatzki, T. (2002), The Site of the Social: A Philosophical Account of the Constitution of Social Life and Change, University Park: Pennsylvania State University Press.

Schatzki, T. (2010), "Materiality and social life", Nature and Culture, Vol.5 No.2, pp.123-149.

Schatzki, T. (2012), “A primer on practices”, In Higgs, J., Barnett, R., Billett, S., Hutchings, M., and Trede, F. (Eds.), Practice-Based Education: Perspectives and Strategies, Rotterdam: Sense Publishers, pp.13-26.

Secker, J., \& Coonan, E. (2011). A new curriculum for information literacy: Curriculum and supporting documents (pp.1-41). Retrieved from https://newcurriculum.wordpress.com/project-reports-and-outputs/

Shoham, S. and Strauss, S.K. (2007), "Information needs of North American immigrants to Israel", Journal of Information, Communication and Ethics in Society, Vol.5 No.2/3, pp.185-205.

Sin, S-C. J., \& Kim, K-S. (2013), “International students' everyday life information seeking: The 
informational value of social networking sites", Library and Information Science Research, Vol.35, pp.107-116. doi:10.1016/j.lisr.2012.11.006

Tsai, T.-I. (2010), "Information horizons of Taiwanese graduate students", In iConference proceedings, pp.1-14.

Veinot, T.C. (2009), "Interactive acquisition and sharing: Understanding the dynamics of HIV/AIDS information networks", Journal of the Association for Information Science and Technology, Vol.60 No.11, pp.2313-2332.

Volet, S., \& Jones, C. (2012). "Cultural transitions in higher education: Individual adaptation, transformation and engagement”, In: S. Karabenick \& T. Urdan (Eds.), Transitions across schools and cultures, Bingley: Emerald, pp.241-284.

Wenger, E. (1998), Communities of Practice: Learning, Meaning, and Identity, Cambridge: Cambridge University Press.

Wilson, P. (1983), Second-Hand Knowledge: An Inquiry into Cognitive Authority, Westport, CT: Greenwood Press.

Willson, R. (2016). Information in transition: Examining the information behaviour of academics as they transition into university careers. (Unpublished doctoralisepithesis). Charles Sturt University, Australia. Retrieved from http://primo.unilinc.edu.au/primo_library/libweb/action/dlDisplay.do?vid=CSU2\&do cId=dtl_csu85865 